\title{
Flax Fibers Reinforced Thermoplastic Resin Based Biocomposites, a Future for Sustainable Composite Parts
}

\author{
Laurent Guillaumat ${ }^{1, *}$, Svetlana Terekhina ${ }^{1}$, Imed Derbali ${ }^{1}$, Arthur Monti ${ }^{2}$, \\ Abderahim El Mahi ${ }^{2}$, and Zouhaier Jendli ${ }^{3}$ \\ ${ }^{1}$ LAMPA, ENSAM, 2, bld du Ronceray 49100 Angers, France \\ ${ }^{2}$ LAUM, Avenue Olivier Messeiaen, 72085 Le Mans, France \\ ${ }^{3}$ ESTACA, rue George Charpak, BP 76121, 53061 Laval cedex 9, France
}

\begin{abstract}
One of the major challenges of thermoplastic matrix based composites is to manufacture finished parts both in one shot process and in a reduced time production. For this purpose, two techniques were developed to manufacture eco-friendly composites: one is the stamping using hot and cold airflow and the second one concern a one shot manufacturing of sandwich using infusion process. Then, several quasi-static and dynamic analyses were performed to validate the efficiency of the developed processes and to confirm the good quality of the material.
\end{abstract}

\section{Introduction}

Fibres reinforced composites are increasingly used in aerospace, automotive, marine industries and civil engineering due to their high specific strengths and modulus, stiffness, good corrosion resistance and fatigue properties. However, the use of synthetic fibre reinforced composites may become a problem from health and environmental point of view. One of the particular challenges is to replace the synthetic fibres by vegetal ones [1-2]. Consequently, numerous researches have been carried out on vegetal fibres based composites for some years [3-6]. To reduce the environmental impact while providing high specific properties, the use of vegetal fibre reinforced polymers (VFRP) is being widely investigated. Lots of research have already proven that such materials may be suitable for industrial applications that currently use glass fibre reinforced polymers (GFRP) [7, 8]. Moreover, thermoplastic composites are also widely being studied because they allow the recycling of composite materials - a significant aspect of the end of life management of traditional thermoset composites. These composites can also be tailored to provide other attractive properties for the automotive and aerospace industrials, such as a good forming ability to process large and complex structural parts [9, 10]. Among all vegetal fibres reinforced composites, the flax fibres offer interesting mechanical properties and appear as a green technological solution [11].

\footnotetext{
* Corresponding author: laurent.guillaumat@ensam.eu
} 
The main problem for industries is the time to produce parts. Therefore, recent developments aiming to reduce production time while keeping good properties of structural parts are carried out. For example, short carbon fiber/PEEK structures were successfully obtained by thermocompression only around 40 minutes at $400{ }^{\circ} \mathrm{C}$ which is the melting temperature of the resin [12]. Unfortunately, using a hot press equipped with electrical resistances for heating the assembly (mould and material) and the compressed air for the cooling is still far from mass industrial interests. Another review shows that the Roctool company has successfully developed a fast thermal-compression molding process applied to large parts based on thermoplastic composites [13]. This technique consists in heating both the punch and the die and eventually the material by electromagnetic induction current. The cooling of the mould is ensured by injecting cold water through specific channels in the mould.

Results presented in this paper are coming from two PhD thesis (Arthur Monti and Imed Derbali) which dealt with the coupling process - durability trying to reduce the processing time. One way was to investigate a process using hot air flow and the second way was to manufacture bio-sandwichs with one-shot technique using thermoplastic liquid resin.

\section{Materials and manufacturing}

\subsection{Materials}

Two kinds of material are investigated in this study: the first one was a laminated composite flax fibres and Polypropylene matrix and the second one a sandwich composite. Both are manufacturing using thermoplastic matrix. For the first one resin was polypropylene and liquid Acrylic resin for the second one.

\subsubsection{Laminated composites}

For the laminated composite, comingled fabric with different weave architectures were used. These materials were kindly provided by DEPESTELE group. A $2 \times 2$ twill weave fabric (310 $\mathrm{g} / \mathrm{m}^{2}$, areal weight) and a satin weave fabric $\left(280 \mathrm{~g} / \mathrm{m}^{2}\right.$ areal weight $)$ are considered. 300 tex ribbons constitute the warp and weft strands. For both fabrics, the mass fraction depends on direction: $39 \%$ and $61 \%$ for the warp and weft strands respectively. For both materials, the volume fraction of fibres corresponds to around $50 \%$. Because of the use of fabrics the stack of layers respects the following angle direction: $[0 / 90]_{9},[0 / 90]_{18}$ and $[ \pm 45]_{5 \mathrm{~s}}$. The number of the layers has been defined to obtain a sufficient thickness for mechanical tests.

\subsubsection{Sandwich composites}

The skin are made of laminated composite with a $200 \mathrm{~g} / \mathrm{m}^{2}$ dry FlaxTape manufactured by LINEO [14]. It is composed of purely unidirectional technical and elementary flax fibres. The resin used is the innovative ELIUM RT-150 thermoplastic liquid resin produced by ARKEMA [15]. The low viscosity of this resin allows the manufacturing of thermoplastic composites with processes used usually for thermoset composites such as Resin Transfer Moulding. Sandwich structures were produced in one-shot liquid resin infusion process at room temperature, described in a previous work [16]. BALTEK balsa panels with a density of $150 \mathrm{~kg} \cdot \mathrm{m}^{-3}$ were used for the core. 


\subsection{Manufacturing}

\subsubsection{Laminated composites:}

In this study, an experimental airflow thermo-compression device, shown in Fig. 1a, was designed and manufactured at the LAMPA laboratory. The concept consists in shaping the desired number of comingled flax/polypropylene fabrics $\left(180 \times 90 \mathrm{~mm}^{2}\right)$ above the melting point of resin by holding a temperature of $200{ }^{\circ} \mathrm{C}$ during 30 seconds under a given pressure. Hot and cold airflows for rapid heating and cooling are applied respectively. As a result, because of the shape of the available mould, we obtain a V-shaped parts (Fig. 1b).The stamping system is composed of a punch/die commutable couple.

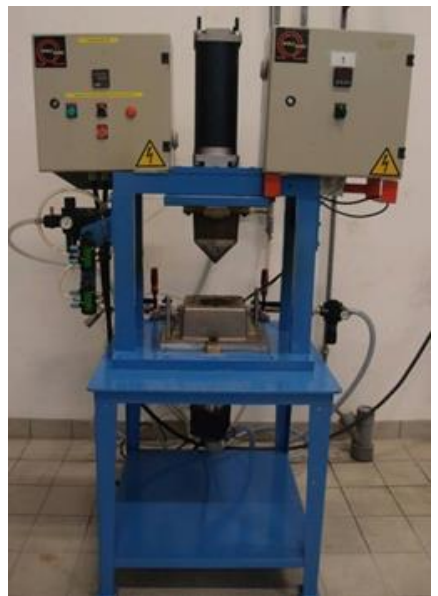

(a)

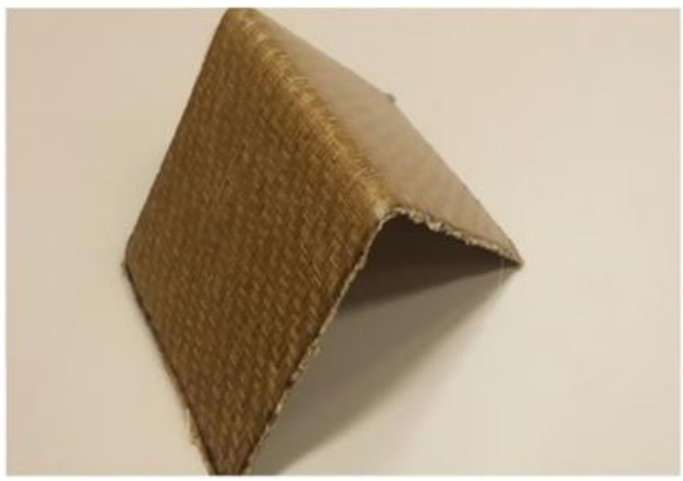

(b)

Fig. 1. (a) Airflow thermo-compression device, (b) V-shape sample.

\subsubsection{Sandwich composites}

For this study we used the infusion technique (Fig. 2) which is made possible by the low viscosity of the new thermoplastic resin. To facilitate the resin infusion, balsa panels cut into regular elementary blocks $(25 \mathrm{~mm} \times 50 \mathrm{~mm} \times 15.9 \mathrm{~mm})$ and assembled as a thin mesh grid were needed. The gaps between adjacent blocks facilitate the migration of the resin from the upper to the lower sides.

Fig. 2. Infusion process.

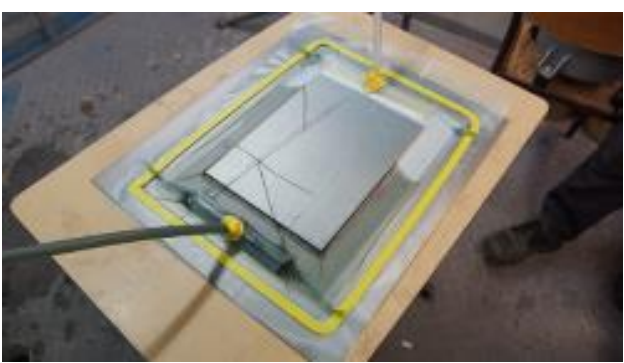




\section{Experimental techniques}

Different techniques were used to measure the mechanical properties of both composite materials.

\subsection{Tensile tests}

A testing machine Zwick with a capacity of $100 \mathrm{kN}$ was used. The principal strains $\varepsilon_{\mathrm{I}}$ and $\varepsilon_{\text {II }}$, used for estimating Young's Modulus and Poisson's ratio, were measured by both strain biaxial gages glued on the samples $\left(90 \times 25 \times 2 \mathrm{~mm}^{3}\right)$ and an extensometer. Each test was conducted using a cross-head speed of $2 \mathrm{~mm} / \mathrm{min}$.

\subsection{Shear tests}

The same sample geometry was used. Here, the fibres are oriented at $45^{\circ}$ relative to the load direction according to the EN ISO 14129 standard. The stacking sequence of the composite was $[ \pm 45]_{5 s}$. To calculate the shear modulus from the tensile test two biaxial gages are necessary. One must be glued in the direction of the tensile load and the second one perpendicularly.

\subsection{Three point bending test}

Rectangular specimens $[0 / 90]_{18}$, with dimensions $\left(90 \times 15 \times 4.5 \mathrm{~mm}^{3}\right)$, were cut from V-parts manufactured by using the new device. They were realized according to ISO 14125 standard. The tests were carried out using another Zwick machine with a capacity of $10 \mathrm{kN}$. Tests were conducted at room temperature with $65 \%$ of air humidity by using a cross-head speed of 2 $\mathrm{mm} / \mathrm{min}$. The length/thickness ratio of the sample was 14.2. It allows to neglect the shear behaviour.

The flexural behaviour of sandwich structures was studied using a 3-point bending tests based on both ASTM C393 and ASTM D7249 [17-18] standards. For one of them, labelled [0] skins were made up of 5 unidirectional plies of flax, and for the other one, the skins were made up of 4 plies of flax with a [0/90] stacking sequence. The span length varied from 80 to $250 \mathrm{~mm}$. Short beam tests were used to determine the shear strength of the core whereas long beams tests were used to measure the ultimate properties of faces.

\subsection{Skin core interface strength testing}

Specific tests were used for sandwich samples to assume the interface strength between skins and core. The skin-core interfacial strength was investigated through flatwise tensile tests performed according to the ASTM C297/C297M [19] standard. This experimental test consists in loading sandwich square samples under stress along an axis parallel to the thickness.

\subsection{Fatigue tests}


To investigate the fatigue behaviour of the sandwich structure, 3-point bending dynamic cyclic tests were performed for $[0 / 90]_{\mathrm{s}}$ specimens. Two different span lengths $(\mathrm{d}=110 \mathrm{~mm}$ and $\mathrm{d}=250 \mathrm{~mm}$ ) were used in order to distinguish the flexural and shear dynamic behaviour. The fatigue tests were displacement-controlled with a frequency of $5 \mathrm{~Hz}$. For the span length $\mathrm{d}=250 \mathrm{~mm}$, specimens were loaded with an average displacement $D_{m}$ defined as $50 \%$ of the failure displacement under quasi-static monotonic 3-point bending tests. The amplitude of displacement was then varied in order to increase the loading ratio $r$ defined by:

$$
R=\frac{D_{\max }}{D_{m}}
$$

where $\mathrm{D}_{\max }$ is the maximum displacement applied during the cycle. For the span length $\mathrm{d}=110$ $\mathrm{mm}$, the average displacement $\mathrm{D}_{\mathrm{m}}$ was defined as $40 \%$ of the failure displacement, in order to avoid early core shear failure.

\subsection{Microstructural observations}

Microstructural observations were realized on the tested specimens in order to analyse materials at microscale to find damages. An Axio Ziess Optical Microscope (OM) was used for that in the cross section of the manufactured materials. Additionally, specimens were cut in the cross section and coated with a thin layer of gold in order to be examined with a Zeiss Supra 25 Scanning Electron Microscope (SEM).

\section{Results}

\subsection{Laminated composite manufactured by hot air flow device}

Sample to realize tension loading were cut from the V-shape structures (Fig. 1b) manufactured by the newly-developed thermal-compression device.

As-received samples exhibit porosity and debonding between fibrous yarns and matrix. It is the main problem of this type of material.

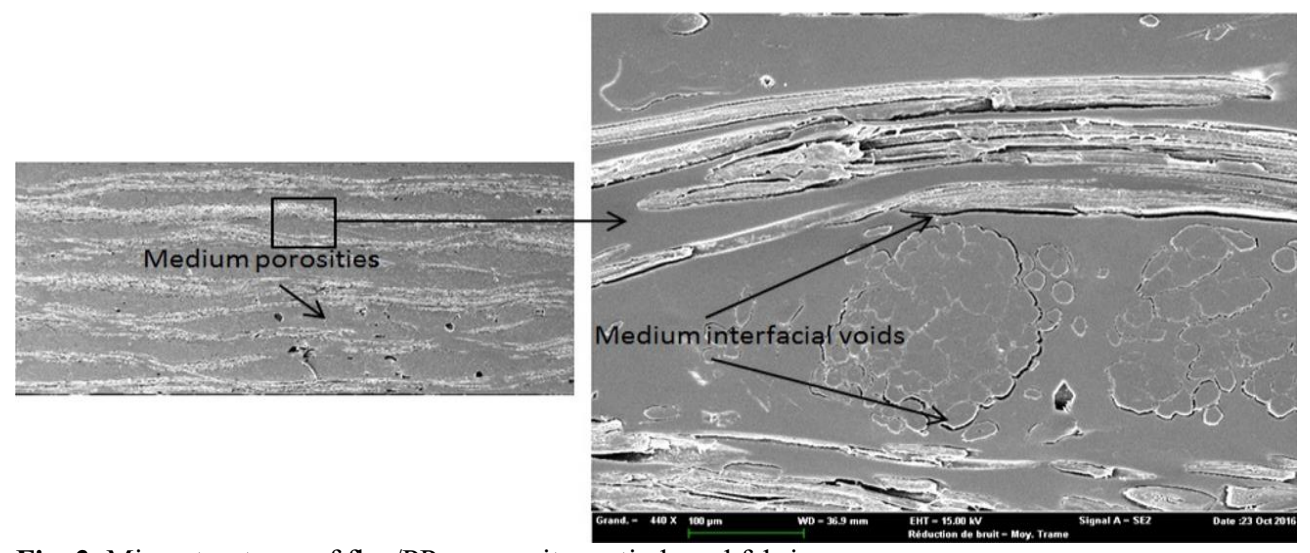

Fig. 3. Microstructures of flax/PP composites satin based fabric.

The three main parameters of the process were investigated and their influences were measured on the mechanical properties using the following experimental design:

- $\quad 1,3$ and 5 bars of pressure at $200{ }^{\circ} \mathrm{C}$ for $30 \mathrm{~s}$; 
- $\quad 0,30,60,120,240 \mathrm{~s}$ of holding time at $200^{\circ} \mathrm{C}$ and 5 bars;

$180,200,220,235$ and $250{ }^{\circ} \mathrm{C}$ under 5 bars for 30 s. The Fig. 4 shows the influence of pressure, temperature and holding time on the tensile behaviour at $200{ }^{\circ} \mathrm{C}$ for $30 \mathrm{~s}$ of flax/PP satin based fabric composites. All these composite samples were loaded in the weft direction.

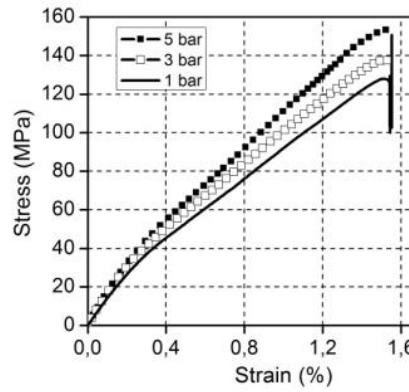

a)

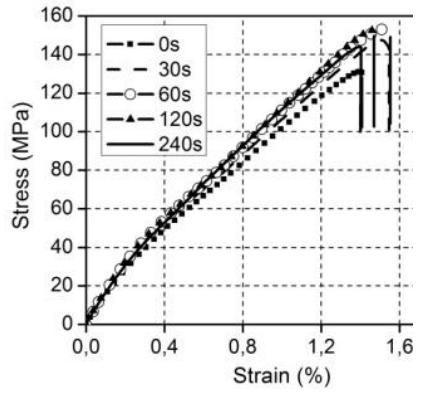

b)

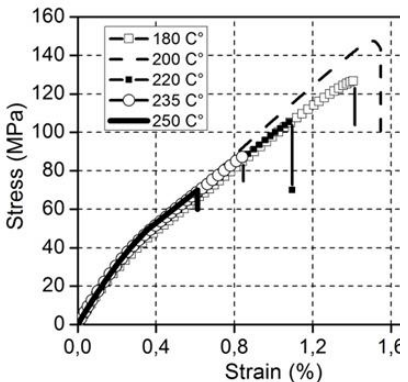

c)

Fig. 4. Influence of pressure (a), holding time effect (b) at $200^{\circ} \mathrm{C}$ for $30 \mathrm{~s}$ and temperature (c) on composite based on weft strand satin fabric made by the new-developed thermal-compression process. A similar bilinear behaviour of the stress-strain evolution for the different applied pressures is observed (Fig. 4a) but significant differences due to the pressure level on the curves can be noticed. Temperature is also a very influential parameter on the quality of the materials produced (Fig. 4c). It requires a precise identification of its optimum value so that to obtain the lowest resin viscosity without degrading the lingo-cellulosic fibres. In general, vegetal fibres do not support high processing temperatures, not higher than around $200{ }^{\circ} \mathrm{C}$. It is possible that the degradation of natural fibres may occur before the resin melts when the processing temperature is too high. More particularly, for flax fibres and polypropylene resin, the melting temperature of resin is around $200{ }^{\circ} \mathrm{C}$ that makes possible this process. In fact, there is a compromise between obtaining good impregnation and avoiding fibres degradation.

The following table gives mechanical properties of the material manufactured by the new process compared to one manufactured using a conventional thermo-compression press. We can notice that values are very close.

Table 1. Tensile properties of composite parts made by new optimized and conventional thermocompression processes.

\begin{tabular}{|c|c|c|c|c|c|c|c|}
\hline Process & Material & $\begin{array}{c}\text { Loading } \\
\text { direction }\end{array}$ & $\begin{array}{c}\mathrm{E} \\
(\mathrm{MPa})\end{array}$ & $\begin{array}{c}\sigma \mathrm{e} \\
(\mathrm{MPa})\end{array}$ & $\begin{array}{c}\sigma_{\text {ult }} \\
(\mathrm{MPa})\end{array}$ & $\varepsilon_{\text {ult }}(\%)$ & $\mathrm{V}$ \\
\hline New device & Satin & Weft & $16.6 \pm 0.5$ & $18.0 \pm 0.5$ & $145 \pm 5$ & 1.50 & 0.12 \\
\hline $\begin{array}{c}\text { Conventional } \\
\text { press }\end{array}$ & Satin & Weft & $16.6 \pm 0.6$ & $18.0 \pm 0.5$ & $133 \pm 5$ & 1.48 & - \\
\hline \multirow{2}{*}{ Process } & Material & $\begin{array}{c}\text { Loading } \\
\text { direction }\end{array}$ & $\begin{array}{c}\mathrm{E} \\
(\mathrm{MPa})\end{array}$ & $\begin{array}{c}\sigma \mathrm{MPa}) \\
(\mathrm{MPa})\end{array}$ & $\varepsilon_{\text {ult }}(\%)$ & $\mathrm{V}$ \\
\hline \multirow{2}{*}{ New device } & Twill & Warp & $9.9 \pm 0.5$ & $11.5 \pm 0.3$ & $94 \pm 5$ & 1.77 & - \\
\cline { 2 - 9 } & \multirow{2}{*}{ Satin } & Weft & $15.5 \pm 0.5$ & $18.0 \pm 0.5$ & $130 \pm 5$ & 1.59 & 0.12 \\
\cline { 3 - 9 } & Weft & $8.8 \pm 0.5$ & $10.0 \pm 0.2$ & $90 \pm 5$ & 2.08 & - \\
\hline
\end{tabular}


The good properties of the skin/core interface are the most important point in sandwich design. Indeed, the flexural properties of structures depend on this parameter at microscale. For this reason, flatwise tensile tests were performed to measure the interfacial strength of this bio-based sandwich and to compare it to those of existing materials. The interfacial failure stress is shown in Table 1, which compares results obtained with those of several authors for different kinds of sandwich materials tested in flatwise tension [20-23].

Table 2. Material properties and skin/core interfacial strength of different sandwich materials.

\begin{tabular}{|c|c|c|c|c|c|}
\hline Specimen & Skin & Core & $\begin{array}{c}\boldsymbol{\rho}_{\mathbf{c}} \\
\left(\mathbf{k g . m} \mathbf{m}^{-3}\right)\end{array}$ & $\begin{array}{c}\boldsymbol{\sigma}_{\mathbf{i}} \\
(\mathbf{M P a})\end{array}$ & Source \\
\hline A & $\begin{array}{c}\text { Carbon Fiber / } \\
\text { Epoxy }\end{array}$ & Aluminum Honeycomb & 39 & 0.8 & Hou et al. 2010 \\
\hline B & Flax/Elium & Balsa core & 150 & 2.3 & Experimental \\
\hline C & Glass/Epoxy & PU foam & 96 & 0.8 & $\begin{array}{c}\text { Tuwair et al. } \\
2015\end{array}$ \\
\hline D & Glass/Epoxy & PP honeycomb & 110 & 0.8 & $\begin{array}{c}\text { Correia et al. } \\
2012\end{array}$ \\
\hline E & Carbon/Epoxy & PU foam & 160 & 1.0 & Sok et al. 2012 \\
\hline
\end{tabular}

Fig. 5. Failure stresses normalized by core density. The specific interfacial strength of the Flax/Elium/Balsa sandwich appears to be very promising, compared to PVC foam sandwiches.

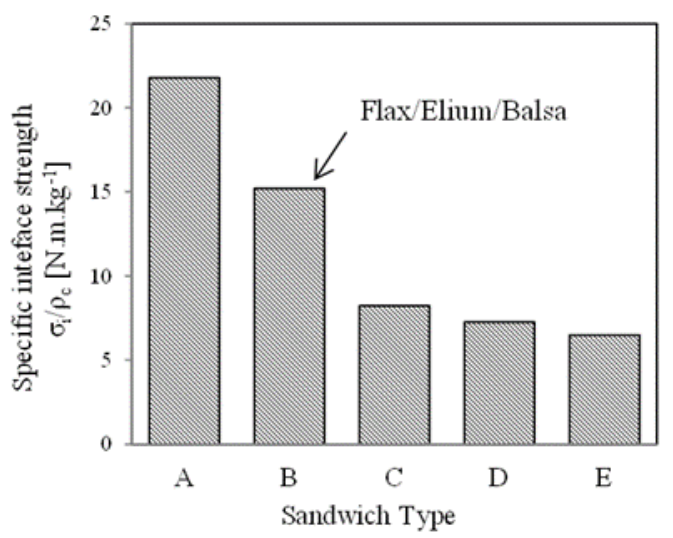

Fig. 5. Flatwise tensile tests results: specific interfacial strength of different sandwich materials.

As sandwich structures are mainly subjected to flexural loadings, different tests were conducted to investigate the flexural behaviour of Flax/Elium/Balsa sandwich beams. First, two sets of $[0]_{5}$ and $[0 / 90]_{\mathrm{s}}$ beams were tested in 3-point bending with a span length of 250 mm. Error! Reference source not found..a presents the Force/Displacement curves obtained. $[0]_{5}$ specimens appear, as expected, stiffer and more resistant due to the higher mechanical properties of the skins. Moreover, the linear elastic domain is more pronounced. On the contrary, $[0 / 90]_{s}$ specimens exhibit a shorter elastic domain and a lower Young modulus followed by a nonlinear behaviour. 


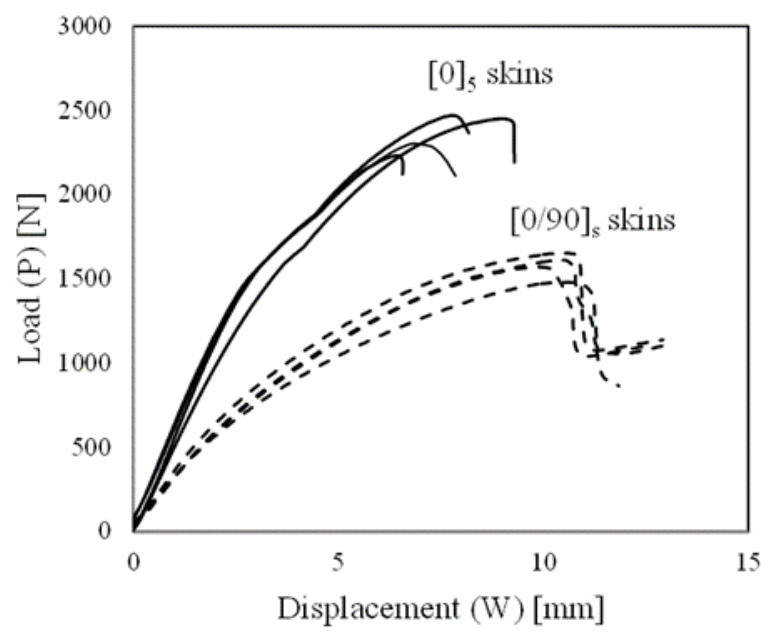

(a)

Fig. 6. Quasi-statique tests performed on sandwich beams with two different skins configuration monotonique 3-point bending.

The Young's modulus of the Flax/Elium skins and the shear modulus of the balsa core can be deduced from equations. Taking into account that $E_{f}$ and $E_{c}$ are respectively the Young's modulus of the skins and the core all data are in the following table.

Table 3. Elastic and ultimate properties of the skins and core.

\begin{tabular}{|c|c|c|c|c|c|c|}
\cline { 2 - 7 } \multicolumn{1}{c|}{} & $E_{f}{ }_{f}^{[0] 5}$ & $\sigma_{f c}^{[0] 5}$ & $E_{f}^{[0 / 90] s}$ & $\sigma_{f c}^{[0 / 90] s}$ & $G_{c}$ & $\tau_{c}$ \\
\hline Unit & $\mathrm{GPa}$ & $\mathrm{MPa}$ & $\mathrm{GPa}$ & $\mathrm{MPa}$ & $\mathrm{MPa}$ & $\mathrm{MPa}$ \\
\hline Average & 24 & 120 & 11 & 90 & 225 & 2.5 \\
\hline Standard Dev & 1 & 8 & 1 & 7 & 48 & 0.5 \\
\hline
\end{tabular}

To determine the flexural and shear ultimate properties of the sandwich beams, monotonique 3 -point bending tests were performed on $[0]_{5}$ specimens with different span lengths. At least 5 beams were tested up to failure for every boundary condition. For the longest beams, a compressive failure of the upper skin was observed, whereas for the shortest beam, a core shear failure of the core occurred (Fig. 7). The results of $\tau_{\mathrm{c}}$ obtained are presented in Table 3. 


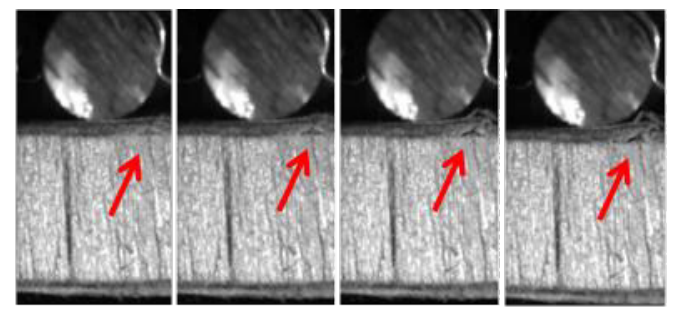

(a)

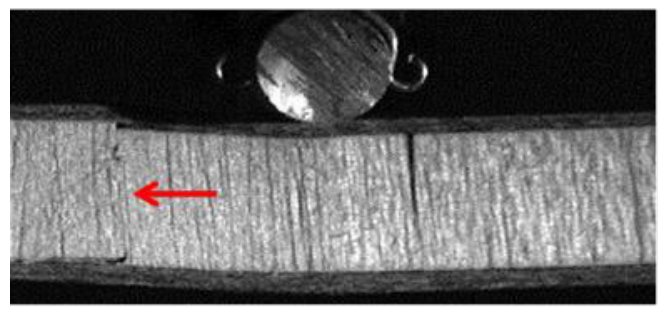

(b)

Fig. 7. Main failure modes observed: a) compressive failure of superior skins and b) core shear failure.

The flexural fatigue behaviour of [0/90] Flax/Elium/Sandwich beams was also investigated. Fatigue tests were performed to determine the lifetime of this structure under different loading ratios and to compare their fatigue performance to those of GFRP-foam cored sandwiches. In this case, two different span lengths were used, $d=110 \mathrm{~mm}$ and $\mathrm{d}=250 \mathrm{~mm}$, in order to analyse the shear and flexural properties of the beams.

It's worth noticing that whatever the loading ratio, beams tested with $\mathrm{d}=110 \mathrm{~mm}$ present a higher degradation rate and fail earlier than beams tested with a span length $\mathrm{d}=250 \mathrm{~mm}$.

For both sets of specimens, endurance diagrams were plotted to determine the end of life according to a $N_{10}$ criterion for different loading ratios $r$. This criterion is satisfied when a 10 $\%$ decrease for the maximal applied load is observed. Fig. 8 presents the Wöhler diagrams corresponding to both span lengths $\mathrm{d}=110 \mathrm{~mm}$ and $\mathrm{d}=250 \mathrm{~mm}$.

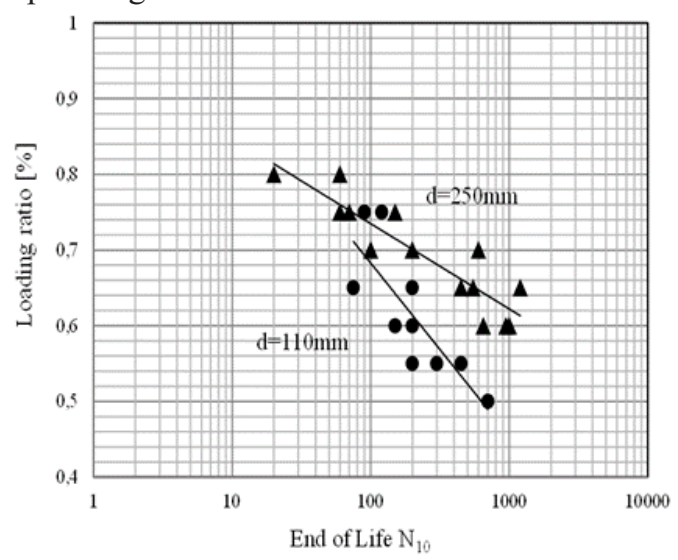

(a)

Fig. 8. Endurance diagram for [0/90]s sandwich beams and for two different span lengths and $b$ ) fatigue performances of the Flax/Elium/Balsa sandwich compared to other non bio-based material 


\section{Conclusions}

This work focuses on the experimental analysis of the static and dynamic flexural properties of bio-based composites: laminated and sandwich materials.

Two processes are used: one was the one shot liquid resin infusion process for the sandwich and the second one was a rapid thermo-compression using a hot air flow process. Both are interesting perspectives in the manufacturing of eco-friendly composite structures.

For the sandwich structure: flatwise tensile tests revealed good interfacial strength for the sandwich. This interesting property was attributed to the use of a low-viscosity resin with an open-cell balsa core made of assembled elementary blocks.

Then, quasi-static 3-point bending tests were performed to determine the elastic and ultimate properties of both skins and core.

Sandwich beams were tested with different span lengths in order to analyse the flexural and shear response of the structure. High scattering of the failure load was observed for a specific span length, corresponding to the transition between a core shear failure mode and a compressive failure mode of the upper skin. In addition, the fatigue behaviour of this material was studied under 3-point bending. The fatigue performances appear slightly lower than those of GFRP/foam cored sandwiches, but remain promising.

For the laminated materials: parameters of the process were optimized using a temperature of $200{ }^{\circ} \mathrm{C}$ and a holding time of $30 \mathrm{~s}$. As expected, the pressure has a strong effect on the void rate in the material and the temperature has to be lower to a given level which induces the degradation of the fibres. The holding time has a slight effect on the quality of the material.

To optimize these parameters the materials manufactured by this new device were compared to those coming from a classical thermo-compression apparatus manufacturing. This comparison has shown that the mechanical properties of the two batches were closed.

One can conclude that these eco-friendly materials would be suitable for some semi-structural applications currently using GFRP/foam sandwich structures and subjected to fatigue loadings.

\section{References}

1. C. Baley, Composite Part A: Applied Science and Manufacturing, 33, 7 (2002)

2. L. Yan, N. Chouw, K. Jayaraman, Composites Part B: 56 (2014)

3. O. Faruk, A. K. Bledzki, H. P. Fink, and M. Sain, Prog. Polym. Sci., 37, 11 (2012)

4. K. G. Satyanarayana, G. G. C. Arizaga, and F. Wypych, Prog. Polym. Sci., vol. 34 (2009)

5. L. Yan, N. Chouw, and K. Jayaraman, Compos. Part B Eng., vol. 56 (2014)

6. L. Yan, B. Kasal, and L. Huang, Compos. Part B, 92 (2016)

7. A. Mancuso, G. Pitarresi, and D. Tumino, Procedia Eng., 109 (2015)

8. O. Castro, J. M. Silva, T. Devezas, A. Silva, and L. Gil, Mater. Des., 31, 1 (2010)

9. D. U. Shah, P.J. Schubel, M.J. Clifford, Composites: Part B, doi: http://dx.doi.org/10.1016/j.compositesb. 27.04.2013

10. M. Zimniewska, J. Myalski, M. Koziol , J. Mankowski, E. Bogacz, Journal of Natural Fibers, Vol. 9, 4 (2012) 
11. R. Joost, Duflou, D. Yelin, K. V Acker, W. Dewulf, CIRP Annals-Manufacturing Technology, 63, 1 (2014)

12. G-P. Picher-Martel , A. Levy , P. Hubert, Composites: Part A, 81 (2016)

13. RocTool «http://www.roctool.com/en/latest-news\#sthash.z653GKsa.dpuf», JEC World, (2016)

14. M. Khalfallah, B. Abbès, F. Abbès, Y. Q. Guo, V. Marcel, A. Duval, F. Vanfleteren, and F. Rousseau, Mater. Des., 64 (2014)

15. R. M. Boumbimba, M. Coulibaly, A. Khabouchi, G. Kinvi-dossou, N. Bonfoh, and P. Gerard, Compos. Struct., 160 (2017)

16. A. Monti, A. El Mahi, Z. Jendli, and L. Guillaumat, Compos. Part B, 110 (2017)

17. ASTM D7249/D7249M : Standard Test Methode for Facing Properties of Sandwich Constructiosn by Long Beam Flexure.

18. ASTM C393/C393M : Standard Test Method for Core Shear Properties of Sandwich Constructions by Beam Flexure."

19. ASTM C297/C297M - 04 : Standard Test Method for Flatwise Tensile Strength of Sandwich Constructions."

20. T.-H. Hou, J. M. Baughman, T. J. Zimmerman, J. K. Sutter, and J. M. Gardner, NASA (2010)

21. H. Tuwair, M. Hopkins, J. Volz, M. A ElGawady, M. Mohamed, K. Chandrashekhara, and V. Birman, Compos. Part B, 79 (2015)

22. J. R. Correia, M. Garrido, J. A. Gonilha, F. A. Branco, and L. G. Reis, Int. J. Struct. Integr., 3, 2 (2012)

23. T. Sok, University of Utah, (2012) 